\title{
BMJ Open Association of breast feeding and birth interval with child mortality in Pakistan: a cross-sectional study using nationally representative Demographic and Health Survey data
}

\author{
Rafi Amir-ud-Din (D) , ${ }^{1}$ Hafiz Zahid Mahmood, ${ }^{1}$ Faisal Abbas, ${ }^{2}$ \\ Muhammad Muzammil, ${ }^{1}$ Ramesh Kumar (D) , ${ }^{3,4}$ Sathirakorn Pongpanich ${ }^{4}$
}

To cite: Amir-ud-Din R, Mahmood HZ, Abbas F, et al. Association of breast feeding and birth interval with child mortality in Pakistan: a crosssectional study using nationally representative Demographic and Health Survey data. BMJ Open 2022;12:e053196. doi:10.1136/ bmjopen-2021-053196

- Prepublication history and additional supplemental materia for this paper are available online. To view these files, please visit the journal online (http://dx.doi.org/10.1136/ bmjopen-2021-053196)

Received 09 May 2021 Accepted 17 November 2021

Check for updates

(c) Author(s) (or their employer(s)) 2022. Re-use permitted under CC BY-NC. No commercial re-use. See rights and permissions. Published by BMJ.

For numbered affiliations see end of article.

Correspondence to

Dr Ramesh Kumar;

drramesh1978@gmail.com

\section{ABSTRACT}

Objectives This study analysed the association between breast feeding (BF) and birth interval (BI) (both succeeding and preceding) with neonatal mortality (NM), infant mortality (IM) and under-5 mortality (U5M).

Design This cross-sectional study used data from the Pakistan Demographic and Health Survey 2017-2018. Settings All provinces, Islamabad and Federally Administered Tribal Areas were included in the analysis. Participants A total of 12769 children born to evermarried multiparous women aged $30-49$ years who gave live birth within 5 years preceding the interview. Multiple births are not included.

Data analysis Multivariate logistic regression analysis was used.

Results We found that BF was associated with nearly $98 \%$ lower risk of NM (OR 0.015; 95\% Cl: 0.01 to 0.03 ; $p<0.001$ ), $96 \%$ lower risk of IM (OR 0.038; 95\% Cl: 0.02 to 0.06; $\mathrm{p}<0.001$ ) and $94 \%$ lower risk of U5M (OR 0.050; $95 \% \mathrm{Cl}$ : 0.03 to $0.08 ; p<0.001)$. Compared with optimal preceding birth interval (PBI) (36+ months), short PBI (<18 months) was associated with around six times higher risk of NM (OR $5.661 ; 95 \%$ Cl: 2.78 to $11.53 ; p<0.001$ ), over five times risk of IM (OR 4.704; $95 \% \mathrm{Cl}: 2.70$ to $8.19 ; \mathrm{p}<0.001$ ) and over five times risk of U5M (OR 4.745; 95\% Cl: 2.79 to 8.07 ; $\mathrm{p}<0.001$ ). Disaggregating the data by child's gender, place of residence and mother's occupational status showed that being ever breast fed was associated with a smaller risk of NM, IM and U5M in all three disaggregations. However, the risk of smaller $\mathrm{PBI}<18$ months was generally more pronounced in female children (NM and U5M) or when the children lived in rural areas (NM, IM and U5M). PBI $<18$ months was associated with greater risk of NM and IM, and smaller risk of U5M when mothers did a paid job.

Conclusion This study's significance lies in the fact that it has found $\mathrm{BF}$ and $\mathrm{BI}$ to be consistent protective factors against NM, IM and U5M. Given Pakistan's economic constraints, optimal BF and BI are the most cost-effective interventions to reduce child mortality.

\section{INTRODUCTION}

In 2019, global neonatal mortality (NM) and under-5 mortality (U5M) rates were 18 and

\section{Strengths and limitations of this study}

- This cross-sectional study has explored two crucial correlates of under-5 child mortality in Pakistan's context using logistic regression: breast feeding and birth interval.

- Breast feeding was interacted with the preceding birth interval (PBI) to test how different PBI categories affected the risk of child mortality given the breastfeeding status of the child.

- This study adjusts the relationship between breast feeding and birth interval and child mortality with several contextual factors such as the child's gender, place of residence and maternal occupational status.

- The cross-sectional nature of the Demographic and Health Survey data does not allow causal inference.

- Using information about the birth history of a child for up to 5 years prior to the mother's interview may cause recall bias.

39 deaths per 1000 live births, respectively. The Sustainable Development Goals (SDGs) targets of the NM and U5M rates were 12 and 25 deaths per 1000 live births. In sharp contrast to the global child mortality rates, $\mathrm{NM}$ and U5M rates in Pakistan were 41 and 67 per 1000 live births, respectively, in 2019. With 44 children dying out of every 1000 live births in the first month of their life, Pakistan had the highest NM rate globally in 2017 . $^{1}$

Existing literature has identified various factors associated with child mortality. The maternal attributes associated with child mortality are education of mother, ${ }^{2}$ mother's age, ${ }^{3}{ }^{4}$ the number of children ever born, birth order of the child, ${ }^{356}$ birth spacing (BS), breast feeding $(\mathrm{BF}),{ }^{7}$ marital status of the mother at the time of last birth ${ }^{2}$ and mother's empowerment. ${ }^{8}$ The gender of the child is also a correlate of child 
mortality. ${ }^{9}$ The household characteristics associated with child mortality are the type of cooking fuel used in the household and kitchen location, urban-rural residential status and household wealth status. ${ }^{10}$ Other factors associated with child mortality are health-seeking behaviour, for example, utilisation of basic health services, ${ }^{11}$ the context of kinship relations ${ }^{12}$ and religion. ${ }^{13}$

Two factors associated with child mortality that notably received academic research and public policy focus are BF and BS. ${ }^{14} \mathrm{BF}$ is associated with a lower risk of diarrhoea, respiratory infection, obesity in childhood and adolescence, and better cognitive development. ${ }^{15}$ According to one estimate, suboptimal BF is responsible for 1.4 million child deaths and 44 million disability-adjusted life years (roughly $10 \%$ in children under 5 years). BF is associated with healthier dietary behaviour at the age of 6 months, and optimal BF with early initiation of BF can reduce the risk of childhood obesity and chronic diseases and hence child mortality. ${ }^{16}$

A significant amount of evidence shows that BS affects the odds of child mortality. One study found that birth interval (BI) less than 18 months was associated with over two times higher risk of child mortality than longer BI. ${ }^{17}$ Some studies that controlled the potential endogeneity of BS variables found that BI of fewer than 6 months was detrimental to the survival of the second child. ${ }^{18}{ }^{19}$ Both short preceding birth interval (PBI) and succeeding birth interval (SBI) are risk factors of child mortality for the index child. ${ }^{17}$ A study in India showed that PBI $(<18$ months) increased the risk of mortality in the neonatal and post-neonatal period. ${ }^{20}$ Short PBI (<18 months) increased the risk of the index (second) child's mortality by $31 \%$ in infancy compared with the child born after 18-24 months. ${ }^{21}$ A study in Nairobi found that during the early childhood period, a short SBI $(<18$ months) was associated with two times higher risk of mortality than a longer SBI ( $>36$ months).$^{22}$

Evidence suggests that short PBI and SBI were risk factors of child mortality. ${ }^{23}$ On the contrary, a study found that the older child was at a higher risk of mortality when the BI between two children was short. ${ }^{24}$ While relatively little evidence exists regarding the optimal BI, Rutstein found that the optimal $\mathrm{BI}$ is between 36 and 59 months, and BI greater than 60 months was also a risk factor. ${ }^{25}$ According to the maternal depletion hypothesis, mothers have insufficient time to recuperate between births, especially if they breast feed their children for long periods, are undernourished or carry out strenuous physical work. ${ }^{26}$

Even if research shows the protective effects of $\mathrm{BF}$ and widely spaced births on infant survival, it is not as clear when the child benefits the most from BF and long BIs and under what conditions. ${ }^{14}$ Additionally, the strength of association between child mortality and $\mathrm{BF}$ and $\mathrm{BI}$ varies across different contexts, with many answered questions regarding the reliability and comparability of cross-country estimates. A recent study on the link between BI and child mortality has shown that the mortality-reducing effect of longer PBI $>36$ months varies regionally and with the level of development, and has a relatively large protective effect against child mortality in the developing countries, but has almost zero effect in highly developed countries. ${ }^{27}$

Even though many studies exist on the determinants of child mortality in Pakistan, ${ }^{28-31}$ according to the best of our knowledge, no study has done an in-depth analysis of the interactive role of $\mathrm{BS}$ and $\mathrm{BF}$ in reducing neonatal, infant and child mortality. Thus, this study tries to fill this gap by comprehensively studying the association of $\mathrm{BF}$ and BS (preceding) with child mortality (neonatal, infant and under-5) in Pakistan using recently available nationally representative Pakistan Demographic and Health Survey (PDHS) (2017-2018). ${ }^{32}$ As indicated earlier, Pakistan needs to reduce child mortality by $63 \%$ to achieve an SDG target of 25 under-5 deaths per 1000 live births by 2030. It is crucial to highlight the link between BF and BS and child mortality using the recent data.

\section{METHODS}

\section{Study design, participants and settings}

This cross-sectional study used data from the PDHS 20172018. The PDHS is a nationally representative data that consists of six administrative units, that is, four provinces (Punjab, Sindh, Khyber Pakhtunkhwa and Baluchistan), Federally Administered Tribal Areas and the capital territory Islamabad. PDHS has a stratified two-stage cluster design. Therefore, sampling weights were used to ensure the representativeness of the data.

We selected 12769 children born to ever-married multiparous women aged 30-49 years who gave live birth within 5 years preceding the interview. As our study deals with BI, we have included only those women in the study who gave birth to at least two children. This study only included single births.

PDHS collects data through four main questionnaires: (1) Household, (2) Biomarker, (3) Women and (4) Men's Questionnaire. In addition to the question about women, the Women's Questionnaire also contains information about the birth history of all of the respondent's children (dead or alive). The birth history of a woman is used to select children for different sections of the questionnaire. This study uses the information of ever-married women aged 15-49 years with the history of live births for the past 10 years preceding the survey. Only the single births were considered for this study because multiple births being a risk factor for child mortality ${ }^{33}$ can potentially bias the results by overestimating the child mortality (figure 1).

\section{Variables}

The outcome variables for this study are NM (death in the first month of birth), infant mortality (IM) (death before completing the first year of life) and U5M (death before 5 years), as mortality can occur because of age-specific reasons. For example, premature birth is more strongly associated with mortality in the first year, and suboptimal $\mathrm{BF}$ is associated with U5M. ${ }^{34}$ Therefore, three different levels of child mortality are analysed in this study. All 


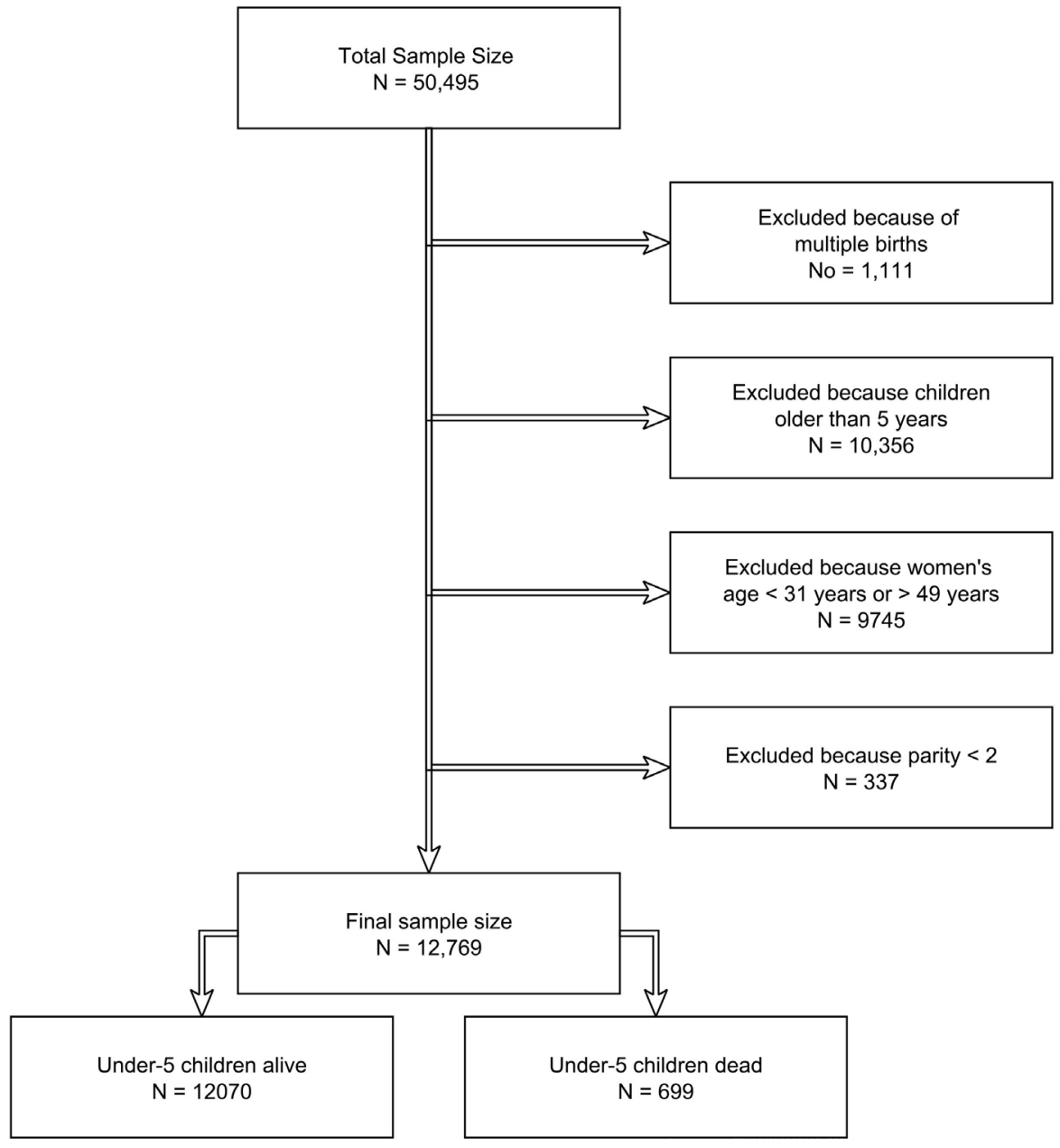

Figure 1 Sample selection flow chart.

three outcome variables, that is, NM, IM and U5M, are binary variables, which are split into 'survived' (reference group) and 'died.'

The first primary exposure variable of interest in this study is BF, which is categorised as 'Never breast fed' as (reference category) and 'Ever breast fed'. The second primary exposure variable of interest in this study is the PBI. Following previous literature, ${ }^{22}$ the variable measuring PBI is categorised into: 'First born,' ' $<18$ months', '18-23 months', '24-35 months' and '36+ months' (reference category).

Some additional child-related, maternal and community-level confounding factors such as birth size and gender of the child, mother's education and current age (categorised into '30-35', '36-40' and ' $>40$ ' years age groups), education of mother and father, place of residence (urban/rural), household wealth status and maternal occupational status are included in the analysis.

\section{Data analysis}

Data for this study are taken from PDHS (2017-2018). This study employed a two-step procedure for data analysis. In the first step, bivariate analysis was done to see the individual association between all response and control variables with the outcome variables. The variables were chosen for multivariate regression analysis based on their theoretical link with child mortality. In the second step, multivariate logistic regression analysis was done to study BF and BI's association with child mortality (NM, IM and U5M).

The previous literature provides insights into how $\mathrm{BF}$ and BI affect each other in terms of their combined effect on the odds of child mortality. ${ }^{35}$ So, we included the interaction term between BF and BI. Besides, a disaggregated analysis was also conducted. We examined the association between $\mathrm{BF}$ and $\mathrm{BI}$ with child mortality by disaggregating data by child's gender, place of residence and mother's occupational status. All statistical analyses were implemented using statistical software STATA/MP V.15.1 (StataCorp, College Station, Texas, USA).

\section{Patient and public involvement}

This study did not involve patients or human subjects directly. The results of the analysis were exclusively based on the data from PDHS.

\section{RESULTS}

Table 1 gives the association of individual, family and community characteristics assumed to be correlated 
Table 1 Association of various individual, family and community-related characteristics with child mortality

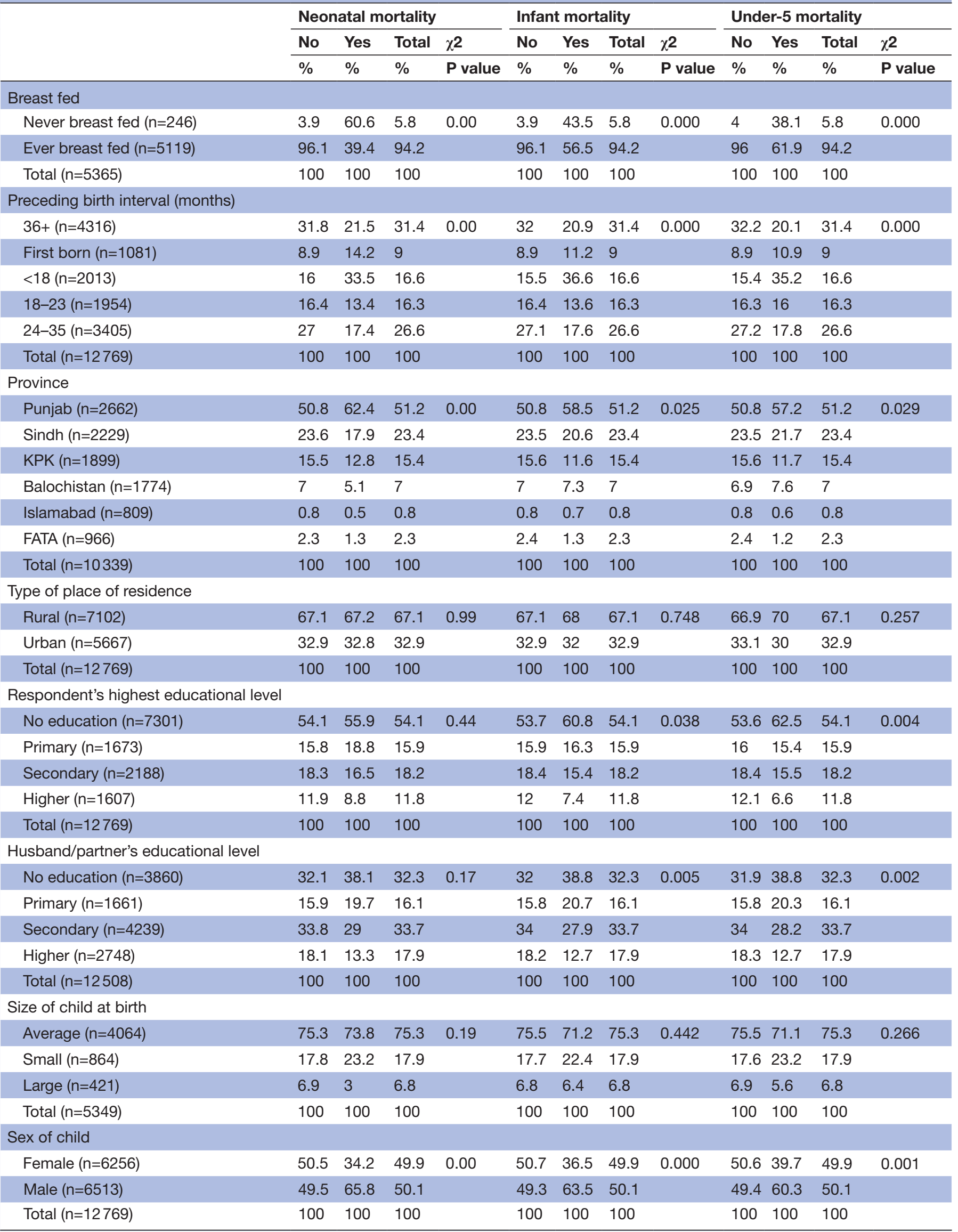




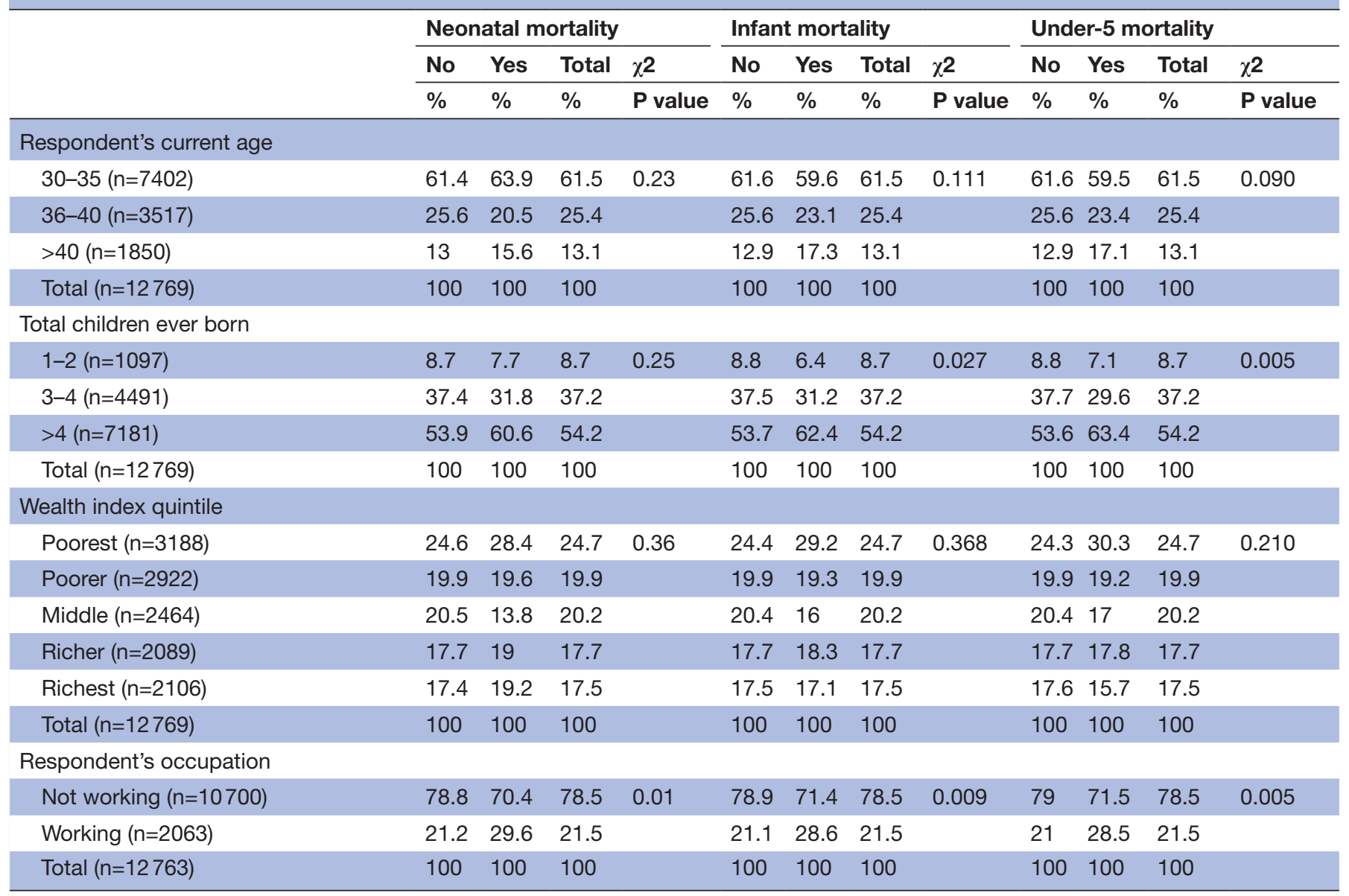

FATA, Federally Administered Tribal Area; KPK, Khyber Pakhtunkhwa.

with neonatal, infant and child mortality. The BF and BI are significantly associated with all three types of child mortality $(\mathrm{p}<0.01)$.

Following the convention in the previous literature, ${ }^{36}$ we retained all the variables in the multivariate regression model either because they were statistically significant or had a theoretical link with child mortality, as shown in table 1 .

Table 2 gives estimates of the multivariate logistic regression model with their OR $(95 \% \mathrm{CI})$ and their $\mathrm{p}$ value. Compared with the cases where a child was never breast fed, having been ever breast fed was associated with nearly $98 \%$ lower risk of NM (OR $0.015 ; 95 \%$ CI: 0.01 to 0.03 ; $\mathrm{p}<0.001$ ), $96 \%$ lower risk of IM (OR 0.038 ; $95 \%$ CI: 0.02 to $0.06 ; \mathrm{p}<0.001)$ and $95 \%$ lower risk of U5M (OR 0.050 ; $95 \%$ CI: 0.03 to 0.08 ; $\mathrm{p}<0.001)$. Compared with optimal PBI (36+ months), short PBI ( $<18$ months) was associated with around six times higher risk of NM (OR $5.661 ; 95 \%$ CI: 2.78 to 11.53 ; $\mathrm{p}<0.001$ ), around five times risk of IM (OR 4.704; 95\% CI: 2.70 to 8.19 ; $\mathrm{p}<0.001)$ and around five times risk of U5M (OR 4.745; 95\% CI: 2.79 to 8.07; $\mathrm{p}<0.001)$.

Given that both BF and BI were significantly associated with child mortality, we also estimated the interaction of $\mathrm{BF}$ and $\mathrm{BI}$ to see the joint risk of no $\mathrm{BF}$ and short PBI (table 3 ). As shown previously (table 2), being ever breast fed remained individually a significant consistent protective factor against NM (OR 0.015; $95 \%$ CI: 0.01 to 0.04 ; $\mathrm{p}<0.001$ ), IM (OR $0.039 ; 95 \%$ CI: 0.02 to 0.08 ; $\mathrm{p}<0.001$ ) and U5M (OR 0.040; 95\% CI: 0.02 to 0.08 ; $p<0.001)$. Similarly, PBI $<18$ months was individually a significant risk factor of NM (OR 4.748; 95\% CI: 1.54 to 14.64; p<0.01), IM (OR 4.848; 95\% CI: 1.58 to $14.85 ; \mathrm{p}<0.01)$ and U5M (OR 3.863; 95\% CI: 1.21 to 12.28 ; $\mathrm{p}<0.05$ ). However, their interaction did not show any significant change in the risk of child mortality (see table 3 ).

\section{Disaggregated analysis}

Following previous literature, ${ }^{37}$ we analysed the association between $\mathrm{BF}$ and $\mathrm{BI}$ with $\mathrm{NM}$, IM and U5M, disaggregating the data by child's gender, place of residence and mother's occupational status, and results are provided in online supplemental tables 1-3 in Appendix. Being ever breast fed was associated with a smaller risk of NM (online supplemental table 1), IM (online supplemental table 2) and U5M (online supplemental table 3) irrespective of whether the child was male or female, the place of residence was rural or urban, or if the mother was engaged in a paid job or did the household work. 
Table 2 Multivariate logistic regression estimates for neonatal, infant and under-5 mortality (full model) - PDHS (2017-2018)

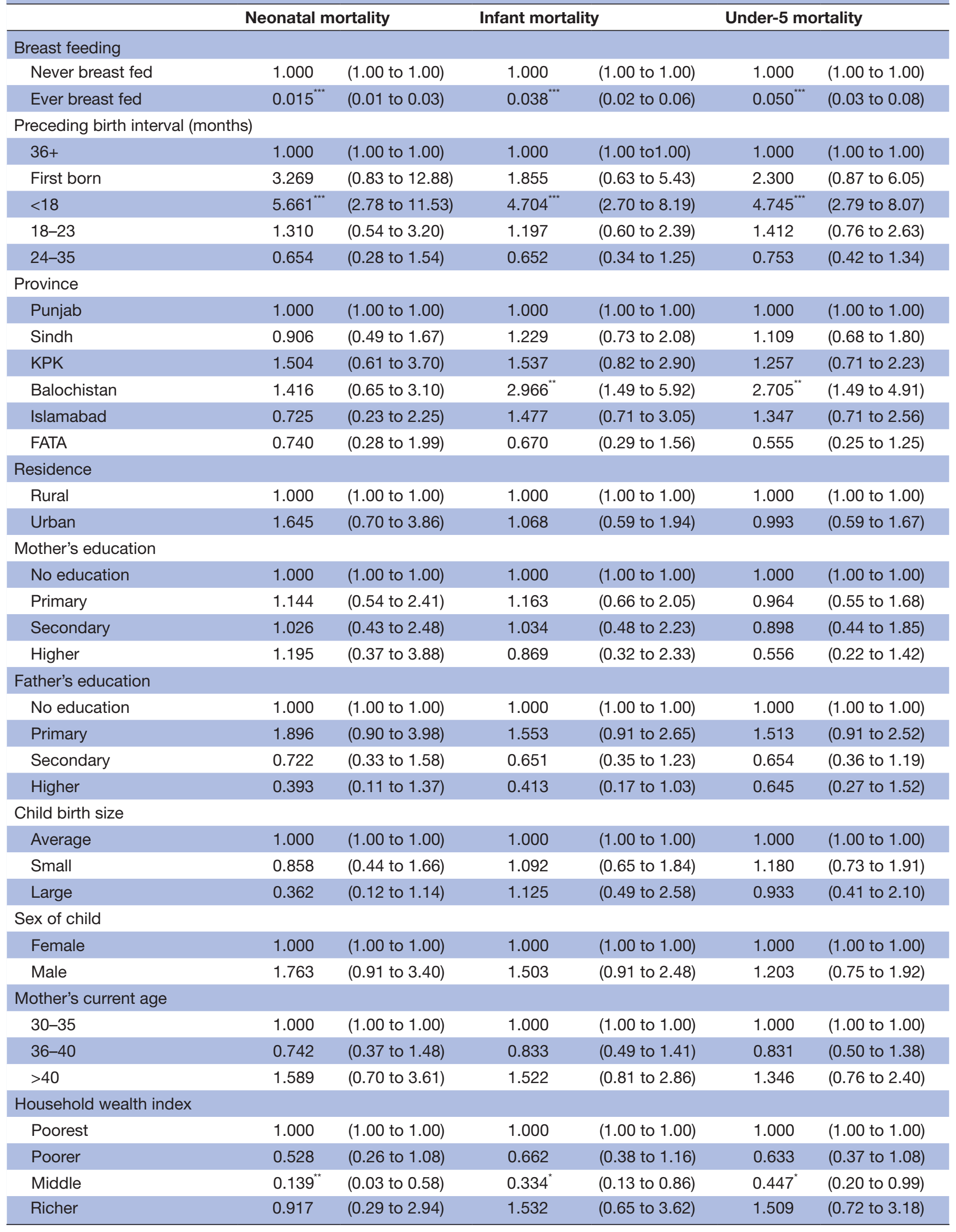


Table 2 Continued

\begin{tabular}{|c|c|c|c|c|c|c|}
\hline \multirow[b]{2}{*}{ Richest } & \multicolumn{2}{|c|}{ Neonatal mortality } & \multicolumn{2}{|c|}{ Infant mortality } & \multicolumn{2}{|c|}{ Under-5 mortality } \\
\hline & 0.559 & (0.11 to 2.93$)$ & 1.118 & (0.37 to 3.40$)$ & 1.030 & (0.39 to 2.73$)$ \\
\hline \multicolumn{7}{|c|}{ Maternal employment status } \\
\hline Working & $2.403^{* *}$ & (1.30 to 4.43$)$ & $1.819^{*}$ & (1.08 to 3.07$)$ & 1.618 & (0.99 to 2.65$)$ \\
\hline $\mathrm{N}$ & 4230.000 & & 4230.000 & & 4230.000 & \\
\hline$P$ value & 0.000 & & 0.000 & & 0.000 & \\
\hline
\end{tabular}

Exponentiated coefficients; $95 \% \mathrm{Cls}$ in brackets.

${ }^{*} \mathrm{P}<0.05,{ }^{* \star} \mathrm{p}<0.01,{ }^{* \star *} \mathrm{p}<0.001$.

FATA, Federally Administered Tribal Area; KPK, Khyber Pakhtunkhwa; PDHS, Pakistan Demographic and Health Survey.

With regard to optimal PBI (36 months or longer), a short PBI $(<18$ months) was associated with nearly six times higher risk of NM for female children (OR 5.991; 95\% CI: 2.17 to $16.55 ; \mathrm{p}<0.001)$ but around five times higher risk of NM for male children (OR 4.808; $95 \%$ CI: 1.84 to $12.54 ; \mathrm{p}<0.01)$. The risk of $\mathrm{PBI}<18$ months was nearly eight times higher than PBI of $36+$ months in rural areas (OR 7.710; 95\% CI: 3.06 to 19.43 ; $p<0.001$ ) but this link was not statistically significant in urban areas. Interestingly, the risk of PBI $<18$ months was again nearly six times higher than $36+$ months PBI in the cases where mothers did not do any paid job (OR 5.855; 95\% CI: 2.35 to $14.62 ; \mathrm{p}<0.001)$ but this risk was even higher in the cases of working mothers (OR 5.929; 95\% CI: 1.95 to 18.01; $\mathrm{p}<0.01$ ) (table 1).

$\mathrm{PBI}<18$ months was associated with higher risk for male infants (OR 4.640; 95\% CI: 2.09 to 10.32; $\mathrm{p}<0.001$ ) than female infants (OR 0.049; $95 \%$ CI: 0.02 to $0.11 ; \mathrm{p}<0.001$ ) (table 2). Unlike NM, PBI $<18$ months was associated with larger risk for the infants when their mother did a paid job (OR 5.771; 95\% CI: 2.07 to 16.08; p<0.001) compared with the infants whose mothers stayed at home (OR 4.624; 95\% CI: 2.26 to $9.45 ; \mathrm{p}<0.001)$.

\section{DISCUSSION}

Multivariate logistic regression results suggest that $\mathrm{BF}$ and BI are associated with child mortality (ie, NM, IM and $\mathrm{U} 5 \mathrm{M})$. This finding was consistent with existing evidence because breast milk has been found to contain the nutrients which provide strong immunity to children against infectious diseases like pneumonia and diarrhoea. ${ }^{38}$ In contrast, suboptimal BF leads to malnourishment and thus leads to mortality. ${ }^{39}$

Short PBI ( $<18$ months) was associated with a higher risk of NM, IM and U5M. Previous studies have also highlighted the role of maternal depletion and sibling rivalry in explaining the link between BI and child mortality. ${ }^{40}$ When the food shortage is chronic, a woman's body prioritises itself over the fetus's needs when faced with making trade-offs concerning energy and nutritional distribution. ${ }^{41}$ Reduced parental attention and a smaller share in the scarce resources (breast milk is a vital resource) may weaken the immune system of index child, and increase the risk of infectious diseases and even mortality. ${ }^{42}$

The link between BF and BI and child mortality disaggregated by a child's gender, place of residence and mother's occupational status also showed that BF was a protective factor against NM, IM and U5M for most of the outcomes. However, disaggregation analysis shows some interesting patterns in child mortality. Female neonates and female children under- 5 show more increased risk of mortality associated with PBI $<18$ months than their male counterparts. In contrast, male infants show more increased risk of mortality associated with $\mathrm{PBI}<18$ months than their female counterparts.

Existing evidence suggests that female children have a biological advantage with respect to the odds of survival. The genetic gender-related differences can explain higher infant mortality among boys as the boys are biologically more vulnerable to diseases than girls. ${ }^{43}$ However, many studies show that gender dimension of child mortality is context specific, and non-biological factors can put any gender at an advantage (or disadvantage) in terms of mortality outcomes. One of these non-biological factors is gender bias against female children. In the contexts where prenatal sex selection is outlawed, a son preference often means large families. So a combination of gender bias against female children and high fertility is associated with excess female mortality. ${ }^{44}$

Contrary to what is generally believed, PBI may not have the uniform mortality-reducing effect on different population groups. As shown in a recent study, the mortality-reducing effect of longer PBI $>36$ months varies regionally and with the level of development, and has a relatively large protective effect against child mortality in the developing countries, but has almost zero effect in highly developed countries. ${ }^{27}$

Compared with rural areas, lower child mortality rates associated with PBI $<18$ months in the urban areas may be explained by the greater availability of communitylevel services such as improved drinking water and sanitation facilities in the urban areas ${ }^{45}$ and better hygienic 
Table 3 Multivariate logistic regression of interaction between breast feeding and preceding birth interval - PDHS (20172018)

Neonatal mortality Infant mortality Under-5 mortality

Length of breast feeding (months)

$\begin{array}{lllllll}\text { Never breast fed } & 1.000 & (1.00 \text { to } 1.00) & 1.000 & (1.00 \text { to } 1.00) & 1.000 & (1.00 \text { to } 1.00) \\ \text { Ever breast fed } & 0.015^{* * * *} & (0.01 \text { to } 0.04) & 0.039^{* * * *} & (0.02 \text { to } 0.08) & 0.040^{* * *} & \text { (0.02 to } 0.08)\end{array}$

Preceding birth interval (months)

\begin{tabular}{|c|c|c|c|c|c|c|}
\hline $36+$ & 1.000 & (1.00 to 1.00$)$ & 1.000 & (1.00 to 1.00$)$ & 1.000 & (1.00 to 1.00$)$ \\
\hline First born & 1.956 & (0.31 to 12.30$)$ & 1.595 & (0.30 to 8.35$)$ & 1.569 & (0.30 to 8.29 ) \\
\hline$<18$ & $4.748^{* *}$ & (1.54 to 14.64$)$ & $4.848^{* *}$ & (1.58 to 14.85$)$ & $3.863^{*}$ & (1.21 to 12.28$)$ \\
\hline $18-23$ & 1.028 & (0.24 to 4.39$)$ & 0.995 & (0.26 to 3.75$)$ & 0.798 & (0.22 to 2.91$)$ \\
\hline $24-35$ & 0.947 & (0.28 to 3.22$)$ & 0.811 & (0.26 to 2.51$)$ & 0.742 & (0.24 to 2.25$)$ \\
\hline Never breast fed (36+) & 1.000 & (1.00 to 1.00$)$ & 1.000 & (1.00 to 1.00$)$ & 1.000 & (1.00 to 1.00$)$ \\
\hline Never breast fed (first born) & 1.000 & (1.00 to 1.00$)$ & 1.000 & (1.00 to 1.00$)$ & 1.000 & (1.00 to 1.00$)$ \\
\hline Never breast fed $(<18)$ & 1.000 & (1.00 to 1.00$)$ & 1.000 & (1.00 to 1.00$)$ & 1.000 & (1.00 to 1.00$)$ \\
\hline Never breast fed (18-23) & 1.000 & (1.00 to 1.00$)$ & 1.000 & (1.00 to 1.00$)$ & 1.000 & (1.00 to 1.00$)$ \\
\hline Never breast fed (24-35) & 1.000 & (1.00 to 1.00$)$ & 1.000 & (1.00 to 1.00$)$ & 1.000 & (1.00 to 1.00$)$ \\
\hline Ever breast fed (36+) & 1.000 & (1.00 to 1.00$)$ & 1.000 & $(1.00$ to 1.00$)$ & 1.000 & (1.00 to 1.00$)$ \\
\hline Ever breast fed (first born) & 2.477 & (0.24 to 25.80$)$ & 1.293 & (0.17 to 9.65$)$ & 1.763 & (0.24 to 12.79$)$ \\
\hline Ever breast fed $(<18)$ & 1.276 & (0.31 to 5.30$)$ & 0.959 & (0.27 to 3.45$)$ & 1.333 & (0.36 to 4.89$)$ \\
\hline Ever breast fed (18-23) & 1.498 & (0.20 to 11.12$)$ & 1.291 & (0.26 to 6.49 ) & 2.165 & (0.46 to 10.16$)$ \\
\hline Ever breast fed (24-35) & 0.332 & (0.06 to 1.82$)$ & 0.687 & (0.18 to 2.63$)$ & 1.012 & (0.28 to 3.64$)$ \\
\hline \multicolumn{7}{|l|}{ Province } \\
\hline Punjab & 1.000 & (1.00 to 1.00$)$ & 1.000 & (1.00 to 1.00$)$ & 1.000 & (1.00 to 1.00$)$ \\
\hline Sindh & 0.962 & (0.51 to 1.82 ) & 1.256 & (0.73 to 2.17 ) & 1.145 & (0.69 to 1.89 ) \\
\hline KPK & 1.540 & (0.62 to 3.85$)$ & 1.553 & (0.82 to 2.94$)$ & 1.259 & (0.70 to 2.25$)$ \\
\hline Balochistan & 1.419 & (0.65 to 3.12 ) & $2.999^{* *}$ & (1.49 to 6.04$)$ & $2.754^{* * *}$ & (1.52 to 5.01 ) \\
\hline Islamabad & 0.744 & (0.24 to 2.34 ) & 1.493 & (0.73 to 3.06 ) & 1.383 & (0.74 to 2.60$)$ \\
\hline FATA & 0.810 & (0.30 to 2.20$)$ & 0.690 & (0.30 to 1.61$)$ & 0.581 & (0.26 to 1.30$)$ \\
\hline \multicolumn{7}{|l|}{ Residence } \\
\hline Rural & 1.000 & (1.00 to 1.00$)$ & 1.000 & (1.00 to 1.00$)$ & 1.000 & (1.00 to 1.00$)$ \\
\hline Urban & 1.649 & (0.73 to 3.72 ) & 1.064 & (0.59 to 1.90$)$ & 0.979 & (0.59 to 1.62 ) \\
\hline \multicolumn{7}{|l|}{ Mother's education } \\
\hline No education & 1.000 & (1.00 to 1.00$)$ & 1.000 & (1.00 to 1.00$)$ & 1.000 & (1.00 to 1.00$)$ \\
\hline Primary & 1.133 & (0.54 to 2.37 ) & 1.173 & (0.66 to 2.09 ) & 0.968 & (0.55 to 1.70$)$ \\
\hline Secondary & 1.019 & (0.43 to 2.40$)$ & 1.039 & (0.48 to 2.24 ) & 0.894 & (0.44 to 1.83 ) \\
\hline Higher & 1.242 & (0.38 to 4.05$)$ & 0.887 & (0.32 to 2.42 ) & 0.561 & (0.22 to 1.45$)$ \\
\hline \multicolumn{7}{|l|}{ Father's education } \\
\hline No education & 1.000 & (1.00 to 1.00$)$ & 1.000 & (1.00 to 1.00$)$ & 1.000 & (1.00 to 1.00 ) \\
\hline Primary & 1.943 & (0.89 to 4.23 ) & 1.549 & (0.90 to 2.65 ) & 1.495 & (0.90 to 2.50$)$ \\
\hline Secondary & 0.701 & (0.32 to 1.55$)$ & 0.639 & (0.34 to 1.21$)$ & 0.649 & (0.36 to 1.18 ) \\
\hline Higher & 0.379 & (0.11 to 1.33 ) & 0.405 & (0.16 to 1.03$)$ & 0.653 & (0.27 to 1.56$)$ \\
\hline \multicolumn{7}{|l|}{ Child birth size } \\
\hline Average & 1.000 & (1.00 to 1.00$)$ & 1.000 & (1.00 to 1.00$)$ & 1.000 & (1.00 to 1.00$)$ \\
\hline Small & 0.859 & (0.45 to 1.66$)$ & 1.088 & (0.64 to 1.84 ) & 1.188 & (0.72 to 1.95 ) \\
\hline Large & 0.338 & (0.11 to 1.05 ) & 1.109 & (0.48 to 2.57 ) & 0.913 & (0.40 to 2.10$)$ \\
\hline
\end{tabular}


Table 3 Continued

\begin{tabular}{|c|c|c|c|c|c|c|}
\hline \multirow[b]{2}{*}{ Female } & \multicolumn{2}{|c|}{ Neonatal mortality } & \multicolumn{2}{|c|}{ Infant mortality } & \multicolumn{2}{|c|}{ Under-5 mortality } \\
\hline & 1.000 & (1.00 to 1.00$)$ & 1.000 & (1.00 to 1.00$)$ & 1.000 & (1.00 to 1.00$)$ \\
\hline Male & 1.681 & (0.88 to 3.21$)$ & 1.478 & (0.90 to 2.44$)$ & 1.175 & (0.74 to 1.87$)$ \\
\hline \multicolumn{7}{|c|}{ Mother's current age } \\
\hline 30-35 & 1.000 & (1.00 to 1.00$)$ & 1.000 & (1.00 to 1.00$)$ & 1.000 & (1.00 to 1.00$)$ \\
\hline $36-40$ & 0.711 & (0.37 to 1.38$)$ & 0.828 & (0.49 to 1.39$)$ & 0.828 & (0.50 to 1.37$)$ \\
\hline$>40$ & 1.548 & (0.67 to 3.58$)$ & 1.520 & (0.81 to 2.87 ) & 1.369 & (0.77 to 2.44$)$ \\
\hline \multicolumn{7}{|c|}{ Household wealth index } \\
\hline Poorest & 1.000 & (1.00 to 1.00$)$ & 1.000 & (1.00 to 1.00$)$ & 1.000 & (1.00 to 1.00$)$ \\
\hline Poorer & 0.563 & (0.27 to 1.15$)$ & 0.673 & (0.38 to 1.18$)$ & 0.646 & (0.38 to 1.11$)$ \\
\hline Middle & $0.141^{\text {** }}$ & (0.04 to 0.56$)$ & $0.337^{*}$ & (0.13 to 0.87$)$ & 0.455 & (0.21 to 1.01$)$ \\
\hline Richer & 0.914 & (0.29 to 2.91$)$ & 1.545 & (0.65 to 3.66$)$ & 1.533 & (0.73 to 3.22$)$ \\
\hline Richest & 0.544 & (0.11 to 2.74$)$ & 1.119 & (0.37 to 3.37$)$ & 1.008 & (0.38 to 2.67 ) \\
\hline \multicolumn{7}{|c|}{ Maternal employment status } \\
\hline Not working & 1.000 & (1.00 to 1.00$)$ & 1.000 & (1.00 to 1.00$)$ & 1.000 & (1.00 to 1.00$)$ \\
\hline Working & $2.334^{* *}$ & (1.23 to 4.43$)$ & $1.803^{*}$ & (1.05 to 3.10$)$ & 1.571 & (0.94 to 2.63 ) \\
\hline $\mathrm{N}$ & 4230.000 & & 4230.000 & & 4230.000 & \\
\hline $\mathrm{F}$ & 8.510 & & 9.311 & & 8.028 & \\
\hline$P$ value & 0.000 & & 0.000 & & 0.000 & \\
\hline
\end{tabular}

Exponentiated coefficients; $95 \% \mathrm{Cls}$ in brackets.

${ }^{*} \mathrm{P}<0.05,{ }^{* *} \mathrm{p}<0.01,{ }^{* * *} \mathrm{p}<0.001$.

FATA, Federally Administered Tribal Area; KPK, Khyber Pakhtunkhwa; PDHS, Pakistan Demographic and Health Survey.

standards of mothers and caregivers associated with better education and access to public health messages. ${ }^{46}$

Similarly, a mother's paid work is associated with increased risk of NM and IM caused by PBI $<18$ months, but a mother's paid work protects against U5M. Though these results seem puzzling, evidence regarding the link between the mother's working status and child mortality is also not clear either. One strand of literature sees the mother's paid work as a protective factor against child mortality. Several mechanisms have been suggested to explain lower mortality rates among children of working mothers, such as greater household financial resources, a higher level of autonomy and independence, and more informed social networks and freedom of movement. ${ }^{47} 48$

However, some studies found an increased risk of mortality among children whose mothers worked outside because working mothers were not as likely to breast feed their children as stay-at-home women. ${ }^{49}$ It is also argued that when the children pass the infancy stage, they require complementary food that may not be afforded by the women who do not do any paid work resulting in child malnutrition and mortality ${ }^{50}$ which corroborates our finding that $\mathrm{U} 5 \mathrm{M}$ is lower among children whose mothers do a paid job.

The data used in this study are the largest nationally representative dataset, and the results of the study can be generalised at the national and subnational levels and can be used for better policy formulation and effective interventions. Still, the study has a few limitations. As the analysis is based on cross-section survey data, we cannot infer any causal relationship between BF and BI. Additionally, we used information about the birth history of a child for up to 5 years prior to the mother's interview. Consequently, the retrospective data may, therefore, result in a recall bias.

\section{CONCLUSION}

$\mathrm{BF}$ and optimal BI were protective factors against NM, IM and U5M. Analysis of the data disaggregated by the child's gender, residential status and maternal occupational status showed that $\mathrm{BF}$ was a protective factor against NM, IM and U5M for most stratifications. In contrast, BI had a differential effect on the odds of child mortality with respect to the gender of the child, urbanrural residential status and maternal occupational status. Given household-level economic and social constraints in Pakistan, optimal BF and BI are the most cost-effective interventions to reduce child mortality. Increasing the information about the protective role of BS against child mortality may be another effective intervention.

\section{Author affiliations}

${ }^{1}$ Department of Economics, COMSATS University Islamabad, Lahore Campus, Lahore, Pakistan

${ }^{2}$ Department of Economics, School of Social Sciences and Humanities (S3H), National University of Sciences and Technology, Islamabad, Pakistan 
${ }^{3}$ Department of Public Health, Health Services Academy, Islamabad, Pakistan ${ }^{4}$ College of Public Health Sciences, Chulalongkorn University, Bangkok, Thailand

\section{Twitter Faisal Abbas @Faisal61115}

Acknowledgements The authors acknowledge the funding provided by the Higher Education Commission of Pakistan under Thematic Research Grant Programme FY 2017-2018 and acknowledge the support by Rachadapisek Sompote Fund for Postdoctoral Fellowship, Chulalongkorn University, Thailand. The authors also acknowledge the valuable help of research assistants Masood Ur Rehman and Umm-e-Zainab.

Contributors RA-u-D and ZM performed the literature search and conceptualised this study. FA and MM did data analysis. The manuscript was drafted by RK and FA, final manuscript reviewed by SP and RA-u-D. All the authors were involved in revision and editing of the draft. All authors critically reviewed the final manuscript and approve the draft for final submission. RA-U-D act as guarantors.

Funding The authors have not declared a specific grant for this research from any funding agency in the public, commercial or not-for-profit sectors.

Competing interests None declared.

Patient consent for publication Obtained.

Ethics approval This study used DHS data. ICF Institutional Review Board (IRB) approved the data collection process, which involved taking informed consent from respondents. Permission to use the data from all included countries was granted by Measure DHS. We acquired permission from DHS programme to use the data in this study subject to treatment of data as confidential, and use of data for only research purposes, and submission of copy of resulting publication to DHS programme. For surveys recently conducted (surveys conducted after 2010), the DHS programme follows the standard DHS protocol under that was approved by the IRB of ICF. The IRB of ICF complied with the US Department of Health and Human Services requirements for the 'Protection of Human Subjects' (45 CFR 46). The current ICF IRB reference number is: FWA00002349.

Provenance and peer review Not commissioned; externally peer reviewed.

Data availability statement Data are available in a public, open access repository. Data used are freely available and can be accessed from Demographic and Health Survey website.

Supplemental material This content has been supplied by the author(s). It has not been vetted by BMJ Publishing Group Limited (BMJ) and may not have been peer-reviewed. Any opinions or recommendations discussed are solely those of the author(s) and are not endorsed by BMJ. BMJ disclaims all liability and responsibility arising from any reliance placed on the content. Where the content includes any translated material, BMJ does not warrant the accuracy and reliability of the translations (including but not limited to local regulations, clinical guidelines, terminology, drug names and drug dosages), and is not responsible for any error and/or omissions arising from translation and adaptation or otherwise.

Open access This is an open access article distributed in accordance with the Creative Commons Attribution Non Commercial (CC BY-NC 4.0) license, which permits others to distribute, remix, adapt, build upon this work non-commercially, and license their derivative works on different terms, provided the original work is properly cited, appropriate credit is given, any changes made indicated, and the use is non-commercial. See: http://creativecommons.org/licenses/by-nc/4.0/.

\section{ORCID iDs}

Rafi Amir-ud-Din http://orcid.org/0000-0003-4100-3382

Ramesh Kumar http://orcid.org/0000-0002-9701-3179

\section{REFERENCES}

1 Hug L, Sharrow D, Zhong K. Unicef. levels \& trends in child mortality: report 2018, estimates developed by the United Nations inter-agency group for child mortality estimation (UN IGME). United Nations Children's Fund, 2018.

2 Shifa GT, Ahmed AA, Yalew AW. Socioeconomic and environmental determinants of under-five mortality in Gamo Gofa zone, southern Ethiopia: a matched case control study. BMC Int Health Hum Rights 2018;18:14

3 Kravdal $\varnothing$. New evidence about effects of reproductive variables on child mortality in sub-Saharan Africa. Popul Stud 2018;72:139-56.

4 Marphatia AA, Ambale GS, Reid AM. Women's marriage age matters for public health: a review of the broader health and social implications in South Asia. Front Public Health 2017;5:269.
5 Khan JR, Awan N. A comprehensive analysis on child mortality and its determinants in Bangladesh using frailty models. Arch Public Health 2017;75:58.

6 Maniruzzaman M, Suri HS, Kumar N, et al. Risk factors of neonatal mortality and child mortality in Bangladesh. J Glob Health 2018;8:010417.

7 Ogbo FA, Eastwood J, Page A, et al. The impact of sociodemographic and health-service factors on breast-feeding in sub-Saharan African countries with high diarrhoea mortality. Public Health Nutr 2017;20:3109-19.

8 Stiyaningsih $\mathrm{H}$, Wicaksono F. Impact of Women's Empowerment on Infant Mortality in Indonesia. Kesmas-Natl Public Health $\mathrm{J}$ 2017;11:185-91.

9 Ezeh OK. Trends and population-attributable risk estimates for predictors of early neonatal mortality in Nigeria, 2003-2013: a crosssectional analysis. BMJ Open 2017;7:e013350.

10 Anyamele OD, Ukawuilulu JO, Akanegbu BN. The role of wealth and mother's education in infant and child mortality in 26 Sub-Saharan African countries: evidence from pooled demographic and health survey (DHS) data 2003-2011 and African Development Indicators (ADI), 2012. Soc Indic Res 2017;130:1125-46.

11 Chadoka-Mutanda N, Odimegwu CO. Maternal health-seeking behaviour and under-five mortality in Zimbabwe. J Biosoc Sci 2017;49:408-21.

12 Dong $\mathrm{H}$, Manfredini M, Kurosu S, et al. Kin and birth order effects on male child mortality: three East Asian populations, 1716-1945. Evol Hum Behav 2017;38:208-16.

13 Akseer N, Kamali M, Bakhache N, et al. Status and drivers of maternal, newborn, child and adolescent health in the Islamic world: a comparative analysis. Lancet 2018;391:1493-512.

14 Lindstrom DP, Berhanu B. The effects of breastfeeding and birth spacing on infant and early childhood mortality in Ethiopia. Soc Biol 2000;47:1-17.

15 Ip S, Chung M, Raman G, et al. Breastfeeding and maternal and infant health outcomes in developed countries. Evid Rep Technol Assess 2007;18:15-16.

16 Perrine CG, Galuska DA, Thompson FE, et al. Breastfeeding duration is associated with child diet at 6 years. Pediatrics 2014;134:S50-5.

17 Perin J, Walker N. Potential confounding in the association between short birth intervals and increased neonatal, infant, and child mortality. Glob Health Action 2015;8:29724.

18 Winikoff B. The effects of birth spacing on child and maternal health. Int J Gynecol Obstet 1987;25:219-38.

19 Makepeace G, Pal S. Effects of birth interval on child mortality: evidence from a sequential analysis. World Health Popul 2006;8:69-82.

20 Whitworth A, Stephenson R. Birth spacing, sibling rivalry and child mortality in India. Soc Sci Med 2002;55:2107-19.

21 Gubhaju BB. Effect of birth spacing on infant and child mortality in rural Nepal. J Biosoc Sci 1986;18:435-47.

22 Fotso JC, Cleland J, Mberu B, et al. Birth spacing and child mortality: an analysis of prospective data from the Nairobi urban health and demographic surveillance system. J Biosoc Sci 2013;45:779-98.

23 Lamichhane R, Zhao Y, Paudel S, et al. Factors associated with infant mortality in Nepal: a comparative analysis of Nepal demographic and health surveys (NDHS) 2006 and 2011. BMC Public Health 2017;17:53.

24 Bella H, Khalil MS, Al-Almaie SM, et al. The effects of birth interval on intellectual development of Saudi school children in Eastern Saudi Arabia. Saudi Med J 2005;26:741-5.

25 Rutstein SO. Effects of preceding birth intervals on neonatal, infant and under-five years mortality and nutritional status in developing countries: evidence from the demographic and health surveys. Int $J$ Gynecol Obstet 2005;89:S7-24.

26 Aizenman DE. [Impact of family planning on maternal-child health. The future of humanity depends on our children]. Profamilia 1988;4:28.

27 Molitoris J, Barclay K, Kolk M. When and where birth spacing matters for child survival: an international comparison using the DHS Demography 2019:56:1349-70.

28 Cleland JG, Sathar ZA. The effect of birth spacing on childhood mortality in Pakistan. Popul Stud 1984;38:401-18.

29 Helova A, Hearld KR, Budhwani H. Associates of neonatal, infant and child mortality in the Islamic Republic of Pakistan: a multilevel analysis using the 2012-2013 demographic and health surveys. Matern Child Health J 2017;21:367-75.

30 Sathar ZA. Infant and child mortality in Pakistan-some trends and differentials. J Biosoc Sci 1985;17:351-60.

31 Zakaria M, Tariq S, UI Husnain MI. Socio-economic, macroeconomic, demographic, and environmental variables as determinants of child mortality in South Asia. Environ Sci Pollut Res Int 2020;27:1-11. 
32 National Institute of Population Studies (NIPS) [Pakistan] and ICF. Pakistan demographic and health survey 2017-18. Islamabad, Pakistan, and Rockville, Maryland, USA.

33 Abate MG, Angaw DA, Shaweno T. Proximate determinants of infant mortality in Ethiopia, 2016 Ethiopian demographic and health surveys: results from a survival analysis. Arch Public Health 2020;78:4.

34 Lee GE, Willis K. Long-term effects of premature birth. in: the longterm impact of medical complications in pregnancy. CRC Press 2017:205-24.

35 Zhang Z. Model building strategy for logistic regression: purposeful selection. Ann Transl Med 2016;4:111.

36 Ghawadra SF, Abdullah KL, Choo WY, et al. Psychological distress and its association with job satisfaction among nurses in a teaching hospital. J Clin Nurs 2019;28:4087-97.

37 Sun J. Her voice in the making: ICTs and the empowerment of migrant women in Pearl River Delta, China. Asian J Women Stud 2016;22:507-16.

38 Victora CG, Bahl R, Barros AJD, et al. Breastfeeding in the 21st century: epidemiology, mechanisms, and lifelong effect. Lancet 2016;387:475-90.

39 Lamberti LM, Fischer Walker CL, Noiman A, et al. Breastfeeding and the risk for diarrhea morbidity and mortality. BMC Public Health 2011;11:S15

40 Molitoris J. The effect of birth spacing on child mortality in Sweden, 1878-1926. Popul Dev Rev 2017;43:61-82.
41 Ellison PT. Energetics and reproductive effort. Am J Hum Biol 2003;15:342-51.

42 Tariku L. Effects of preceding birth intervals on child mortality in Ethiopia; evidence from the demographic and health surveys, 2016. Epidemology Int J 2019;3.

43 Pongou R. Why is infant mortality higher in boys than in girls? A new hypothesis based on preconception environment and evidence from a large sample of twins. Demography 2013;50:421-44.

44 Guilmoto CZ, Saikia N, Tamrakar V, et al. Excess under-5 female mortality across India: a spatial analysis using 2011 census data. Lancet Glob Health 2018;6:e650-8.

45 Dhrifi A. Health-care expenditures economic growth and infant mortality: evidence from developed and developing countries, 2018.

46 Sastry N. What explains rural-urban differentials in child mortality in Brazil? Soc Sci Med 1997;44:989-1002.

47 Bloom SS, Wypij D, Das Gupta M. Dimensions of women's autonomy and the influence on maternal health care utilization in a North Indian City. Demography 2001;38:67-78.

48 Mehari K, Wencheko E. Factors affecting maternal health care services utilization in rural Ethiopia: a study based on the 2011 EDHS data. Ethiop J Health Dev 2013;27:16-24.

49 Titaley CR, Dibley MJ, Agho K, et al. Determinants of neonatal mortality in Indonesia. BMC Public Health 2008;8:232.

50 Black RE, Victora CG, Walker SP, et al. Maternal and child undernutrition and overweight in low-income and middle-income countries. Lancet 2013;382:427-51. 